\title{
Liberdade morfológica: possibilidades e limites de um direito a modificar o próprio corpo
}

\author{
Morphological freedom: possibilities and limits of a right to modify one's own body
}

\author{
Carlos Nelson Konder* \\ Cintia Muniz de Souza Konder ${ }^{*}$
}

\section{Resumo}

O artigo dedica-se a examinar as normas jurídicas que permitem e limitam o exercício da chamada liberdade morfológica, consistente no direito a modificar o próprio corpo. Para tanto, são abordadas tanto as modificações corporais com fins estéticos, relativas à identificação social, como aquelas dotadas de objetivos funcionais, voltadas à adição ou ampliação de capacidades. Sobre as primeiras, é discutida a superação dos rígidos limites impostos pelo artigo 13 do Código Civil, em prestígio da principiologia constitucional, mais especificamente da proteção ao pluralismo, à saúde, à dignidade e da vedação à discriminação. Já quanto às segundas, por outro lado, observou-se que essa mesma principiologia dá destaque à liberdade, à isonomia e à privacidade.

Palavras-chave: Corpo. Integridade física. Identidade pessoal. Dignidade da pessoa humana. Autonomia.

\section{Abstract}

\begin{abstract}
The article is dedicated to examining the legal norms that are at stake to allow and limit the exercise of what has been called "morphological freedom", i.e., the right to modify one's own body. To this end, this paper approaches both body modifications for aesthetic purposes related to social identification and those with functional objectives aimed at adding or expanding capacities. About the body modifications, the article discusses the overcoming of the strict limits imposed by article 13 of the Civil Code, in the prestige of the constitutional principle, more specifically the protection of pluralism, health, dignity, and the prohibition of discrimination. Concerning the second, on the other hand, it was observed that this same principle emphasizes freedom, isonomy, and privacy.
\end{abstract}

Keywords: Body. Physical integrity. Personal identity. Dignity of the human person. Autonomy.

\section{Introdução}

A diversificação cultural reconhecida pelo pluralismo aliada ao desenvolvimento da tecnologia médica contribuíram para ampliar as possibilidades de escolha da pessoa humana no que tange a modificar a forma de seu próprio corpo, tanto para alcançar a imagem que reputa adequada à sua própria identidade, como para lhe permitir capacidades e sentidos que perdera ou que jamais possuiu, total ou integralmente. Entretanto, tendo em vista as circunstâncias extremas a que isso pode chegar, coloca-se em questão até que ponto ou em que condições o direito tutela essa que vem sendo referida como liberdade morfológica.

Para examinar de forma mais sistemática as normas jurídicas em jogo que servem a fundamentar ou limitar o exercício desse direito a modificar o próprio corpo, serão apartadas as hipóteses em que a modificação tem fins estéticos, para a construção da própria identidade, examinadas inicialmente, das hipóteses de modificação com o objetivo de ampliar ou recuperar funcionalidades do corpo, abordadas em seguida.

Dessa forma, o presente artigo destina-se a examinar essas duas modalidades de exercício da liberdade morfológica, buscando estabelecer seus fundamentos e contornos a partir do confronto com as regras e, especialmente, dos princípios pertinentes aos dilemas que seu exercício coloca. da Pontifícia Universidade Católica do Rio de Janeiro (PUC-Rio). Doutor (2009) e Mestre (2005) em Direito Civil pela UERJ. Especialista (2009) em Direito Civil pela Università di Camerino (Itália). Bacharel (2003) em Direito pela PUC-Rio. Advogado. E-mail: c.konder@gmail.com Federal Fluminense (UFF), graduada pela Faculdade Nacional de Direito da UFRJ. Advogada. E-mail: mscintia@gmail.com 


\section{A liberdade de realizar modificações corporais estéticas}

Ao regular o uso do próprio corpo, o Código Civil brasileiro preconiza uma norma geral de indisponibilidade: a redação do seu artigo 13 determina que, ressalvadas algumas exceções, "é defeso o ato de disposição do próprio corpo". Seja por conta da influência do pensamento cartesiano, seja da religiosidade de matriz cristã, que encaram o corpo como um receptáculo material da alma, a legislação reproduz o tabu existente sobre o corpo: intocável, sagrado, inacessível à própria pessoa, especialmente por ser associado ao mundano e à sexualidade.

Com efeito, o diploma legal expressa valores dominantes do período histórico do qual se origina: embora promulgado em 2002, tem origem em um projeto realizado no final da década de 1960 e início da década de 1970, gerado, portanto, no auge da ditadura militar. Ademais, o dispositivo em exame encontra inspiração no art. $5^{\circ}$ do Código Civil italiano de 1942, redigido durante o regime fascista. ${ }^{1}$

Os três critérios referidos pela legislação para excepcionar essa indisponibilidade - ou para confirmá-la, a depender do ponto de vista - são igualmente reflexos de padrões culturais históricos. Esses padrões, contudo, conflitam potencialmente com o pluralismo e a não discriminação preconizados pelo constituinte como fundamento e objetivo da República, respectivamente, bem como com a leitura renovada da laicidade que deve guiar o ordenamento: "a laicidade, além de princípio de organização institucional e social, manifesta-se agora também como princípio de governo da vida" (RODOTÀ, 2018, p. 139).

O primeiro critério, de normalização, diz respeito à permanência da modificação ("diminuição permanente da integridade física"), e visaria a evitar que o sujeito tomasse uma decisão sobre sua saúde cujos efeitos não seriam remediados pelo decurso do tempo, priorizando a disposição de partes regeneráveis (SCHREIBER, 2011, p. 39). Sob o pretexto paternalista de proteger a saúde do sujeito contra sua própria vontade, na verdade, o critério apenas impede que as pessoas tenham corpos cuja estrutura fuja daquele padrão socialmente reputado normal, controverso desde a abordagem de Canguilhem (2011, passim). Com efeito, Teixeira destaca como "só por meio do controle do corpo, da autodeterminação corporal é que será possível a efetiva tutela da saúde" (2010, p. 55). Fosse aplicado a rigor, o critério inviabilizaria práticas recorrentes e socialmente toleradas e mesmo valorizadas, como cirurgias plásticas estéticas.

O segundo critério, de moralização, refere-se a atos de disposição que violem os bons costumes. A referência a esse conceito, carregado de insegurança e incerteza sobre seu significado, deita raízes numa tradição de restrição à autonomia existencial, como se observa no âmbito da censura durante a ditatura militar no Brasil (CASTRO, 2017, p. 112). Com efeito, qualquer leitura do termo que não seja guiada estritamente pela tutela de direitos e garantias fundamentais abrirá a porta para restrições incompatíveis com a proteção do pluralismo constitucionalmente garantido.

O terceiro critério, de medicalização, vincula-se à ressalva de "exigência médica". Trata-se de forma intensa de paternalismo clínico, que vai na contramão das tendências da bioética e da ética médica contemporânea voltadas a empoderar o paciente e sua autonomia contra a tradicional ditadura de que "o médico sabe o que é melhor" (OLIVEIRA, 2005, p. 61). A redação do dispositivo é especialmente simbólica, pois em primeiro lugar, em vez da referência mais comum à "finalidade terapêutica" (ligado à saúde do paciente), fala de "exigência médica", como se o médico tivesse o poder de exigir uma modificação corporal do paciente, contra a sua vontade.

Em segundo lugar, a construção frasal do dispositivo, formulada pela negativa (vedando os atos de disposição, salvo exigência médica), cria a leitura de que a liberdade do paciente quanto ao seu corpo é a exceção e a proibição a regra: a única liberdade admitida é a do médico, e não a do paciente. Esse tipo de formulação levou entre nós, por exemplo, a transexualidade a ser tratada como doença, pois somente o diagnóstico de "transexualismo" autorizava a cirurgia de transgenitalização, subordinando a autonomia e a identidade ao estigma da doença (KONDER, 2013, p. 361).

O contraste do rigor da legislação com a realidade social é flagrante. Como todo tabu, a indisponibilidade do corpo é contraditada pela generalizada atração às modificações corporais nas mais diversas culturas e épocas. Retratam isso de forma mais incisiva as imagens históricas de práticas como o Kisedjê, o disco labial dos indígenas brasileiros, o padaung, os anéis de bronze usados pelas mulheres do sudeste asiático e da África, e o ritual do $O$ $\mathrm{KeePa}$, dos indígenas norte-americanos, que eram elevados por ganchos presos à própria pele dentro das cabanas como forma de ascensão espiritual.

"Art. 5. Atti di disposizione del proprio corpo - Gli atti di disposizione del proprio corpo sono vietati quando cagionino una diminuzione permanente della integrità fisica, o quando siano altrimenti contrari alla legge, all'ordine pubblico o al buon costume (1418)". 
Entretanto, mesmo na cultura mainstreamentre nós, hoje são recorrentes modificações corporais como brincos, piercings, tatuagens e implantes de silicone em seios e glúteos, bem como "aparelhos ortodônticos, clareamento e aplicação de resina nos dentes, bronzeamento artificial, cremes redutores de medidas, técnicas de alisamento e implante de cabelo, depilação definitiva" etc. (STANCIOLI; CARVALHO, 2011, p. 274). Difunde-se mais amplamente a constatação de que "uma pessoa só 'tem' ou 'possui' seu corpo (Körper) na medida em que ela 'é' esse corpo vivo (Leib) - na realização da sua vida" (HABERMAS, 2010, p. 70). Essa significativa transformação é relatada do ponto de vista histórico e antropológico:

O corpo outrora motivo de vergonha e restrições, a partir das necessidades econômicas, dos desdobramentos culturais, esquadrinhado e desvendado pela ciência, torna-se paulatinamente elemento de consumo - levando também a essa prática -, sendo submetido, todavia, a uma nova ordem disciplinar: na mesma medida em que fica mais exposto, também se torna mais sujeito a novas normas de comportamento, suscetível a estratégias comerciais, enquadrado pelos ditames relacionados à saúde e ao bem-estar (nada mais compreensível, afinal, se se lembrar que a ambiguidade é uma das marcas da modernidade). (MELO, 2011. p. 509)

É nesse contexto que se compreendem casos como o de Erik Sprague, um dos pioneiros na chamada body art, que, após um doutorado em filosofia com bolsa integral em Nova York passou a se dedicar integralmente às artes performáticas, tatuando setenta por cento do seu corpo com escamas verdes e assumindo o nome de "homem-lagarto", como forma de questionar como as pessoas atribuem significado às ideias de "pessoa" e "ser humano" (SPRAGUE, 2003). Em linha similar, Maria José Cristerna, 38 anos, mexicana, formada em direito, mãe de quatro filhos, que, como liberação frente às agressões constantes e abusos em casa de seu marido, tatuou quase $100 \%$ de seu corpo e inseriu chifres de titânio no crânio e implantes dentários de "presa" como símbolos de força, para ser conhecida como "mulher vampiro" (MULHER VAMPIRO, 2018).

Rick Genest, por sua vez, cobriu cerca de oitenta por cento do corpo buscando retratar "o corpo humano como um corpo em decomposição, a arte de um cadáver apodrecendo": o "menino zumbi" foi recrutado por Nicola Formichetti, diretor de moda da Lady Gaga, para trabalhar como modelo e se popularizou ao participar de um de seus videoclipes (RICK GENEST, 2019).

Entre nós, Priscilla Davanzo, mestre pela Universidade Estadual Paulista (Unesp) com uma dissertação sobre "o corpo obsoleto", e atualmente desenvolvendo tese de doutorado na Faculdade de Belas Artes da Universidade do Porto, cujo tema aborda a interatividade analógica durante o processo criativo em arte e sua relação com o afeto, ficou conhecida pelo trabalho de arte As vacas comem duas vezes a mesma comida, no qual a artista produziu manchas na própria pele similares à das vacas utilizando a técnica da tatuagem: a obra pretende evidenciar o quanto essas transformações corporais (no caso, a tatuagem) oferecem o caráter de perpétuo a determinada área alterada do corpo, como se essa parte específica do corpo não se transformasse com o tempo, estabelecendo, então, uma metáfora da imortalidade, do físico persistente, durável (FREY, 2014).

Enfim, cite-se ainda Stelios Arcadiou, nascido em 19 de junho de 1946, em Limassol, no Chipre, pai de duas filhas, que ocupou até 2007 o cargo de Principal Research Fellow na Performance Arts Digital Research Unit da Nottingham Trent University em Nottingham, Inglaterra: um artista performático (Stelarc) cujas obras concentram-se fortemente no futurismo e na extensão das capacidades do corpo humano, mais especificamente em torno do conceito de que o corpo humano é obsoleto, e cuja performance mais famosa foi desenvolver, por cultura celular, uma orelha no próprio antebraço (STELARC, 2020).

O amparo normativo a essas práticas não pode acontecer por meio da interpretação literal dos rígidos critérios impostos pela vetusta redação do artigo 13 do Código Civil, mas sim pela normativa que lhe é superior. Além dos já citados preceitos referentes ao pluralismo, à não discriminação e à laicidade, o princípio fundamental da dignidade da pessoa humana tem por corolário a tutela da autonomia corporal e, como se vem reconhecendo nas últimas décadas, o direito à identidade pessoal.

Trata-se de construção voltada à defesa da pessoa contra a imputação de características que não sejam compatíveis com a maneira pela qual ela é conhecida no meio social e que se enriqueceu graças à abordagem interdisciplinar, convertendo-se na garantia do próprio processo dinâmico de construção dialógica da identidade (KONDER, 2018, passim). Na medida em que a identidade se molda pelo reconhecimento do outro, a tutela do livre desenvolvimento da personalidade demanda a proteção da liberdade de escolher os valores, atributos, características e preferências que tornam a pessoa ela mesma no diálogo com os demais (TAYLOR, 1997, p. 53). 
Pluralismo, não discriminação, dignidade, autonomia e identidade pessoal convergem para constituir esse emancipador estatuto jurídico do corpo, que se sobrepõe às limitações do direito codificado. Sintetiza Heloísa Helena Barboza: "O corpo juridificado, politizado, medicalizado, torna-se cada vez mais, ao longo da vida, expressão da individualidade, em todas as suas manifestações culturais, religiosas, políticas, sentimentais, enfim numa diversidade de aspectos que, em seu conjunto, constroem a identidade de cada ser humano" (2013, p. 9).

Deve-se ressaltar, todavia, especialmente em um contexto de excessos de vaidade impelido pelas mídias sociais, que embora a liberdade morfológica resguarde a pessoa com relação à possibilidade de modificar o próprio corpo com fins estéticos, não dá guarida à conduta de terceiros que venham a colaborar para a realização de modificações corporais que sejam nitidamente incompatíveis com a tutela de sua saúde, podendo ensejar sua responsabilização por danos sofridos pelo titular, ainda que com seu consentimento. Tome-se o exemplo do tatuador Brendan McCarthy, conhecido por ter arrancado o mamilo de um cliente e ter feito uma fenda na língua de outro, que foi responsabilizado por retirar a orelha de um cliente em 2015, sem anestesia, a despeito do seu consentimento (PRESS ASSOCIATION, 2019).

Ao lado das manifestações de identidade pessoal, voltadas a fins artísticos e estéticos de individualização, sem prejuízo da tutela da saúde, a tecnologia abre espaço para outra linha de modificações corporais: aquelas voltadas ao melhoramento do uso do corpo. Em viés funcional, voltam-se a superar limites e aumentar as possibilidades da pessoa humana. Nesse ponto, contudo, o salto dado nas últimas décadas é ainda mais significativo.

\section{A liberdade de realizar modificações corporais funcionais}

Nenhum dos já referidos e controversos critérios previstos pelo artigo 13 do Código Civil para os atos de disposição do corpo - permanência da disposição (normalidade), afronta aos bons costumes (moralidade), exigência médica (medicalização) - parece impedir as mais tradicionais modificações corporais funcionais. Lentes intraoculares, próteses que substituem membros amputados ou dentes perdidos, válvulas cardíacas artificiais, todas sempre foram acolhidas como sinais de progresso e de mais qualidade de vida, atendendo simultaneamente à autonomia e saúde do titular e às orientações médicas. Em certo sentido, seriam apenas a evolução natural de instrumentos externos ao corpo, como óculos de grau, bengalas, andadores, cadeiras de roda e aparelhos ortodônticos, reputados "exteriores ao Eu" e suprimento de necessidades (SILVA, 2009, p. 75).

Entretanto, nos últimos anos popularizaram-se intervenções sobre o próprio corpo em que tais tecnologias não se destinavam a reparar uma habilidade perdida, mas a desenvolver aptidões já existentes ou mesmo adicionar capacidades jamais possuídas. Inspirados pelo termo cunhado por Julius Huxley na década de 50, transumanismo, reúnem-se defensores da possibilidade de que o ser humano modifique seu próprio corpo aprimorando-se continuamente nos aspectos físico, mental e emocional graças à tecnologia, entre os quais se destaca Max More (MORE, 1990, passim).

Pode-se referir ao exemplo de Neil Harbisson, que, nascido com um tipo extremo de daltonismo que só o permite enxergar em preto e branco, desenvolveu e implantou um chip com uma antena que capta a cor do objeto e, por meio da condução óssea, o torna capaz de "ouvir as cores", pois cada cor toca um som distinto (SOUZA, 2019). Indo mais longe, a hacker escocesa Lepht Anonym já fez mais de cinquenta cirurgias caseiras sem anestesia ou médicos para implantar microchips e imãs no próprio corpo com o objetivo de ampliar seus conhecimentos e sentidos (HOPKINS, 2018). Entretanto, talvez o caso mais chocante seja o do cientista chinês He Jiankui, que anunciou, em novembro de 2018, que editou os genes de duas gêmeas para torná-las resistentes ao HIV, o que poderá reduzir a expectativa de vida das bebês, além do desenvolvimento de outros efeitos ainda impossíveis de prever (GALLAGHER, 2019).

Casos como esse geram reações, entre aqueles que se convencionou chamar de bioconservadores, a defenderem o resguardo à natureza original do ser humano. Nessa linha, destaca-se o perigo de transformar terapias ou medicamentos originariamente criados para o tratamento de doenças ou transtornos - como o aprimoramento da memória e dos músculos, o hormônio do crescimento e as tecnologias reprodutivas - em "um instrumento de melhoria e escolha do consumidor" (SANDEL, 2004, p. 16-17). A reação parece fundada quando se observa que esse aspecto da liberdade morfológica não abrangeria somente dispositivos físicos, mas também a intervenção química, como as chamadas smart drugs: medicamentos prescritos para o tratamento de problemas clínicos, mas que foram generalizados pela pressão social e passaram a ser administrados por indivíduos saudáveis a fim de potencializar sua capacidade cognitiva (MOHAMED, 2016, p. 33). 
Entretanto, destaca Rodotà que a polarização entre aqueles que sustentam ter direito a utilizar a tecnologia para aprimorar seus corpos sem limites e aqueles que buscam restaurar os direitos da natureza não ajuda a esclarecer os termos que devem guiar o direito nesse embate (2012, p. 355). Leciona o autor que os princípios fundamentais do direito devem ser recuperados para abordar essas situações, de modo que a aceitabilidade social do transumanismo, em um ambiente democrático, dependa da capacidade de garantir a segurança das tecnologias, a sua acessibilidade a todos em condições iguais e o respeito ao direito de cada um de governar seu corpo livremente (2012, p. 344).

Tome-se o exemplo de Gabriel Licina, membro fundador do extinto Science for the Masses, grupo independente de pesquisadores que, trabalhando em uma garagem, buscava realizar experimentações e democratizá-las na internet: pingou em seus próprios olhos uma mistura a partir de clorina e6, adaptando um remédio para "cegueira noturna", o que the teria permitido identificar em $100 \%$ das vezes objetos escondidos entre árvores a uma distância de 50 metros em baixa luminosidade, enquanto o grupo que não utilizou a substância identificou apenas $30 \%$ dos objetos (VAIANO, 2016). Até que ponto se poderia reputar presente o exercício legítimo da liberdade morfológica, garantido pelo direito, em casos como esse?

A questão central, pelo que se indica, "é o de procurar entender até que ponto se possa levar o progresso, já que é sempre necessário assegurar a tutelada dignidade da pessoa humana" (CICCO, 2013, p. 03). Nesse sentido, tem-se o caso paradigmático do CEO da Ascendance Biomedical, ativista e biohacker Aaron Traywick, conhecido por se injetar com compostos de terapia genética sem conhecimento médico e incentivar que outros o fizessem e que faleceu afogado em um tanque de flutuação em um spa, tendo a autópsia encontrado a substância cetamina em seu organismo (TONG, 2020).

No cenário nacional, os conflitos decorrentes do direito a modificar o próprio corpo costumavam ser solucionados com a suplantação das rigorosas regras do art. 13 do Código Civil pelos princípios constitucionais do pluralismo, não discriminação, dignidade e autonomia. A partir das novidades vindas com a filosofia transumanista, as inovações corporais passam a ser diferentes, culminando em conflitos singulares, de sorte que o raciocínio deve ser outro.

A controvérsia sobre o merecimento de tutela do direito a realizar modificações corporais funcionais sob a ótica transumanista perpassa, inicialmente, pela análise do art. $5^{\circ}$, caput, da Constituição da República, no que concerne ao direito à liberdade e ao exercício da autonomia da pessoa humana. Com efeito, a habitual utilização da tecnologia naturalmente gera algum nível de dependência, desde o nível da utilização cotidiana da bengala para andar até a necessidade do marcapasso para sobreviver.

Entretanto, a referência à escravidão perante as máquinas se coloca em outros termos quando se pensa que, quanto mais complexos e desenvolvidos esses implantes corporais, mais dependentes eles serão de custosas manutenções e recorrentes atualizações. Cumpre ao direito, portanto, conceber garantias para que a pessoa e seu corpo não se tornem reféns do arbítrio do fornecedor de produtos e serviços para esse fim.

Este direito do próprio indivíduo se autorregular, tal qual uma esfera individual de autoridade e poder, limitado pelo ordenamento jurídico, reflete o princípio que dá o tom para o início das reflexões jurídicas, visto que é à luz desta autonomia que o homem pode exercer o chamado consentimento livre e esclarecido. Desde o Código de Nuremberg, em resposta às atrocidades praticadas nos campos de concentração nazistas, o consentimento informado generalizou-se como requisito para experimentos científicos e intervenções sobre o corpo humano de modo geral. ${ }^{2}$

O consentimento informado ou livre e esclarecido é uma anuência qualificada pela exigência de um procedimento em que sejam explicados de forma completa e pormenorizada todos os aspectos da intervenção, incluindo sua natureza, objetivos, métodos, duração, justificativa, possíveis males, riscos e benefícios, alternativas existentes, nível de confidencialidade dos dados, liberdade total para recusar ou interromper o procedimento em qualquer momento, tudo isso feito em um procedimento dialógico e em linguagem adequada (não técnica) (KONDER, 2003, p. 61).

Ainda com a finalidade de fomentar o exame do merecimento de tutela à luz dos princípios constitucionais, o contexto de modificações corporais com o objetivo de melhoramento - enhancement - desafia a verificação do princípio da isonomia. As mudanças corporais para fins funcionais, especialmente em virtude do súbito salto tecnológico, coloca em xeque tanto a tradicional igualdade formal ou de oportunidades, pela qual todos são tratados

Sobre o tema, v. CASABONA, 2005, e BARBOZA, 2008. 
de forma idêntica pela norma, como a igualdade substancial, entendida como tratar de forma diferenciada aqueles que se encontram em situações distintas. ${ }^{3}$

$\mathrm{Na}$ esfera desportiva, por exemplo, a questão já foi colocada no precedente americano PGA Tour, Inc. $v$. Martin, em que se discutia a legitimidade de uso do carrinho de golfe para percorrer o caminho entre os buracos por um jogador que tinha uma condição circulatória que o atrapalhava caminhar. Entretanto, ante o desenvolvimento da tecnologia, tornou-se mais ilustrativo o caso de Oscar Pistorius. Impedido de participar dos jogos olímpicos pela Associação Internacional de Federações de Atletismo, sob o argumento de que as próteses de fibra de carbono que usava nas pernas Ihe davam uma vantagem mecânica de mais de $30 \%$ em comparação com alguém que não use próteses, o atleta teve que recorrer ao Tribunal Arbitral do Esporte em Lausanne, que cassou a decisão em 2008 sob o fundamento de que ainda não havia dados científicos definitivos sobre eventual vantagem (RODOTÀ, 2012, p. 350).

Comparando com o desenvolvimento das cirurgias que reconstroem os tendões do cotovelo ou do pulso de jogadores de golfe ou de beisebol, bem como das próteses que substituem joelhos de jogadores de futebol, coloca-se um limite cada vez mais tênue entre as intervenções que reparam e que melhoram o corpo (RODOTÀ, 2012, p. 350).

A questão da isonomia tem outro lado além da questão das próteses de Pistorius ou do doping nas atividades desportivas. A indagação que se coloca é quando os melhoramentos corporais são considerados exercício legítimo da liberdade morfológica - o que significa a liberdade de aplicar a si mesmo as vantagens da tecnologia, e quando caracterizam uma verdadeira "competição" desleal? Stefano Rodotà destaca como o doping é rejeitado nas atividades desportivas, mas tolerado o uso de drogas entre artistas, como, abstraindo das competições, jamais se negaria a implantação das próteses de Pistorius para permitir a qualquer pessoa caminhar livremente, e alude ao caso de Aimée Mullins, uma atleta que está em condições similares a Pistorius e que tem tido sucesso como modelo porque, segundo alguns, as próteses que integram suas pernas the permitem poses que as demais modelos não conseguem (RODOTÀ, 2012, p. 351).

A liberdade morfológica, especialmente no uso de tecnologias para melhoramentos corporais, desafia um aspecto pouco discutido da isonomia nessa questão: o elemento socioeconômico. Com a evolução das técnicas de aperfeiçoamento para um corpo mais forte e saudável e do desenvolvimento de substâncias para a mente, como as smart drugs, drogas capazes de aumentar a inteligência dos seus usuários, indaga-se se elas estarão restritas àqueles com condições econômicas e sociais específicas? (RODOTÀ, 2012, p. 373)

Não se trata somente de imaginar os perigos de um doping em concursos públicos e processos seletivos, mas de precaver-se contra os riscos, não somente de uma elite mais forte e influente, mas também do que adverte Mário Marcelo Coelho, no sentido de uma sociedade dividida entre os "geneticamente enriquecidos ou melhorados" e os "naturais" (COELHO, 2012, p. 179).

No âmbito da sociedade de informação, a proteção da privacidade encontra especial relevo. À luz dos desenvolvimentos tecnológicos, uma infinidade quase incontrolável de dados pessoais - que definem quem somos - circula a cada segundo, pela rede mundial de computadores, em todos os lugares que requerem o uso de dados biométricos e nos laboratórios que analisam dados biológicos e genéticos.

Nessa nova realidade, a privacidade transcende o clássico direito a estar só para garantir às pessoas algum grau de controle sobre o acesso às suas informações (RODOTÀ, 2012, p. 91). Fala-se, nesse sentido, em uma autodeterminação informativa, que, em última instância, ao atuar como garantia da possibilidade de fazer escolhas pessoais sem a ingerência ou controle externo, traduz-se em verdadeira autonomia existencial (MORAES, 2010. p. 148).

O corpo é cenário para esse dialético embate e aproximação entre privacidade e tecnologia, na medida em que nele se encontra o repositório de dados mais sensíveis sobre quem a pessoa efetivamente é (KONDER, 2013, p. 352-398). Se as restrições às modificações corporais, em nome dos bons costumes, já atingiam incisivamente a autonomia existencial, os chips subcutâneos permitem o acesso externo a dados extremamente sensíveis (SCHREIBER, 2011, p. 32).

Na hipótese de implantes corporais com atividade neuroquímica, trata-se de informações não somente relativas à localização da pessoa pelo GPS, mas à própria condição de saúde, cujo risco de acesso por seguradoras, empregadores e planos de saúde é sensível. O denominado "olho biônico" com implante de retina artificial já é uma realidade que permite aos que o recebem enxergar formas em preto e branco - e por isso identificar faixa de

Entre tantos, v. MELLO, 1996, passim. 
pedestres e algumas formas. Tudo isso com o auxílio de um microchip implantado na retina do paciente e de uma mini câmera montada na estrutura dos óculos (INOVAÇÃO TECNOLÓGICA, 2010).

Dessa forma, verifica-se que também a liberdade morfológica para fins funcionais deve ser reconhecida como uma prerrogativa de emancipação e autodeterminação do sujeito, insuscetível de ser compreendida dentro dos tradicionais limites da legislação civil. Entretanto, sua valoração também deve ser objeto de ponderação, a ser guiada pela principiologia constitucional, em especial, nesse caso pelos princípios de liberdade - aqui especialmente materializada pelo consentimento livre e esclarecido - isonomia e privacidade.

\section{Conclusão}

As reflexões até aqui tecidas são indicativas da existência de uma ampla liberdade morfológica, consistente no direito do sujeito de modificar o próprio corpo, como forma de autodeterminação pessoal. Essa prerrogativa, para a análise de seus fundamentos e limites, pode ser decomposta com base nos fins buscados pelo seu exercício: a liberdade morfológica para fins estéticos e a liberdade morfológica para fins funcionais.

O exercício da liberdade morfológica para fins estéticos manifesta-se como mecanismo de construção da identidade pessoal do sujeito, razão pela qual devem ser superados os rígidos limites impostos pelo artigo 13 do Código Civil, referentes à permanência da diminuição, aos bons costumes e à exigência médica, pois traduzem vetores de normalização, moralização e medicalização incompatíveis com a principiologia constitucional. Seus contornos, justamente, devem ser inferidos diretamente dessa normativa, mais especificamente da proteção ao pluralismo, à saúde, à dignidade e da vedação à discriminação.

Já o exercício da liberdade morfológica para fins funcionais vincula-se mais diretamente à esfera de autodeterminação e realização pessoal e torna-se mais controverso quando se atravessa a nebulosa fronteira entre modificações reparadoras de aptidões perdidas e aquelas que adicionam habilidades nunca antes detidas. Nessa seara, foi observado que também será o recurso à principiologia constitucional a guiar o intérprete na delimitação dos seus contornos, mas agora priorizando a referência aos princípios de liberdade - aqui especialmente materializada pelo consentimento livre e esclarecido - isonomia e privacidade.

Conclui-se, assim, que os contornos do direito a modificar o próprio corpo, concebido como liberdade morfológica, tanto exercido para fins estéticos como para fins funcionais, não podem ser compreendidos nos estreitos e arcaicos limites da codificação civil, devendo ser compreendido na totalidade do ordenamento, em especial com atenção à principiologia constitucional pertinente.

\section{Referências}

BARBOZA, Heloísa Helena. A pessoa na era da biopolítica: autonomia, corpo e subjetividade. Cadernos IHU ideias, São Leopoldo, ano 2, n. 194, p. 03-20, 2013.

BARBOZA, Heloisa Helena. Reflexões sobre a autonomia negocial. In: TEPEDINO, G.; 33 - FACHIN, L. E. (coord.). O Direito e o tempo. Rio de Janeiro: Renovar, 2008. p. 407-423.

CANGUILHEM, Georges. O normal e o patológico. 7. ed. Rio de Janeiro: Forense Universtiária, 2011.

CASABONA, Carlos María Romeo. O consentimento informado na relação entre médico e paciente: aspectos jurídicos. In: CASABONA, C. M. R.; QUEIROZ; J. F. (coord.). Biotecnologia e suas implicações jurídicas. Belo Horizonte: Del Rey, 2005. p. 128-172.

CASTRO, Thamis Dalsenter Viveiros de. Bons costumes no direito civil brasileiro. São Paulo: Almedina, 2017.

COELHO, Mário Marcelo. Doping genético, o atleta superior e bioética. Revista Bioethikos, São Paulo, v. 6, n. 2, p. 171-180, 2012. Disponível em: http://www.saocamilo-sp.br/pdf/bioethikos/94/a6.pdf. Acesso em: 02 ago. 2020.

CICCO, Maria Cristina de. Atos de disposição do próprio corpo entre autonomia e dignidade da pessoa humana. Civilistica.com, Rio de Janeiro, ano 2, n. 2, p. 1-12, abr./jun. 2013. Disponível em: http://civilistica.com/atos-dedisposicao-do-proprio-corpo/. Acesso em: 14 jun. 2020. 
FREY, Tales. Priscilla Davanzo: a arte de avacalhar com o corpo imaculado. eRevista Performatus, Inhumas, ano 2, n. 8, jan. 2014. Disponível em: https://performatus.com.br/perfil-de-artista/priscilla-davanzo/. Acesso em: 25 set. 2021.

GALLAGHER, James. A polêmica experiência de edição genética chinesa que pode reduzir expectativa de vida. BBC News Brasil, [S.I.], 3 jun. 2019. Disponível em: https://www.bbc.com/portuguese/geral-48479434. Acesso em: 20 maio 2020.

HABERMAS, Jürgen. O futuro da natureza humana. São Paulo: Martins Fontes, 2010.

HOPKINS, Nancy. All a-borg the biohacking express. Science and Industry Museum, Liverpool, 16 oct. 2018. Disponível em: https://blog.scienceandindustrymuseum.org.uk/all-a-borg-the-biohacking-express/. Acesso em: 11 jun. 2020.

INOVAÇÃO TECNOLÓGICA. Olho biônico com retina artificial está pronto para ser implantado. Inovação Tecnológica, [S.I.], 31 mar. 2010. Disponível em: https://www.inovacaotecnologica.com.br/noticias/noticia. php?artigo=olho-bionico-implante-retina\&id=010110100331\#.XynXiihKiUk. Acesso em: 04 jan. 2020.

KONDER, Carlos Nelson. O consentimento no biodireito: os casos dos transexuais e dos wannabes. Revista Trimestral de Direito Civil, Rio de Janeiro, v. 15, p. 41-71, jul./set. 2003.

KONDER, Carlos Nelson. O alcance do direito à identidade pessoal no direito civil brasileiro. Pensar, Fortaleza, v. 23, n. 1, p. 1-11, 2018.

KONDER, Carlos Nelson. Privacidade e corpo: convergências possíveis. Pensar, Fortaleza, v. 18, n. 2, p. 352398, 2013.

MELLO, Celso Antonio Bandeira de. O conteúdo jurídico do princípio da igualdade. São Paulo: Malheiros, 1996.

MELO, Victor de Andrade. O corpo esportivo nas searas tupiniquins: panorama histórico. In: PRIORE, Mary Del; AMANTINO, Marcia (org.). História do corpo no Brasil. São Paulo: Unesp, 2011. p. 507-529.

MOHAMED, Ahmed Dahir. Smart drugs não existem! Entrevista concedida a Ricardo Machado. Revista do Instituto Humanitas Unisinos, São Leopoldo, ano 16, n. 487, p. 33-36, 2016.

MULHER Vampiro. Wikipédia, Flórida, 5 nov. 2018. Disponível em: https://pt.wikipedia.org/w/index. php?title=Mulher_Vampiro\&oldid=53517894. Acesso em: 5 nov. 2018.

OLIVEIRA, Guilherme. Temas de direito da medicina. Coimbra: Coimbra, 2005.

MORAES, Maria Celina Bodin de. Ampliando os direitos da personalidade. In: MORAES, Maria Celina Bodin de. Na medida da pessoa humana: estudos de direito civil-constitucional. Rio de Janeiro: Renovar, 2010. p.121-148.

PRESS ASSOCIATION. Tattooist 'Dr Evil' jailed for performing ear and nipple removals. The Guardian, Londres, 21 mar. 2019. Disponível em: https://www.theguardian.com/uk-news/2019/mar/21/tattooist-dr-evil-jailed-forperforming-ear-and-nipple-removals. Acesso em: 04 out. 2020.

RICK Genest. Wikipédia, Flórida, 8 jan. 2019. Disponível em: https://pt.wikipedia.org/w/index.php?title=Rick_ Genest\&oldid=53998942. Acesso em: 8 jan. 2019.

RODOTÀ, Stefano. Autodeterminação e laicidade. Tradução: Carlos Nelson de Paula Konder. Revista Brasileira de Direito Civil - RBDCivil, Belo Horizonte, v. 17, p. 139-152, jul./set. 2018.

RODOTÀ, Stefano. Post-umano. In: RODOTÁ, Stefano. Il diritto di avere diritti. Bari: Laterza, 2012. p. 341377.

RODOTÀ, Stefano. Transformações do corpo. Revista trimestral de direito civil, Rio de Janeiro, v. 19, p. 91107, jul./set. 2004. 
SANDEL, Michael. The case against perfection: what's wrong with designer children, bionic athletes, and genetic engineering. The Atlantic, [S.I.], apr. 2004. Disponível em: https://www.theatlantic.com/magazine/ archive/2004/04/the-case-against-perfection/302927/. Acesso em: 12 jun. 2020.

SCHREIBER, Anderson. Direitos da personalidade. São Paulo: Atlas, 2011.

SILVA, Denis Franco. Do humano ao pós-humano: pessoa e autonomia privada no contexto do aperfeiçoamento biônico. 2009. Tese (Doutorado em Direito) - Programa de Pós-Graduação em Direito do Departamento de Direito, Pontifícia Universidade Católica do Rio de Janeiro, Rio de Janeiro, 2009.

SOUZA, Marcelle. Ao ligar chip ao cérebro, ele ouviu cores e iniciou o movimento ciborgue. Tilt UOL, 23 maio 2019. Disponível em: https://www.uol.com.br/tilt/noticias/redacao/2019/05/23/primeiro-ciborgue-da-historiaartista-usa-antena-para-ouvir-as-cores.htm. Acesso em: 23 maio 2020.

SPRAGUE, Erik. Once more through the modified looking glass. The Lizarman, [S.I.], 2003. Disponível em: http://www.thelizardman.com/. Acesso em: 04 ago. 2020.

STANCIOLI, Brunello; CARVALHO, Nara Pereira. Da integridade física ao livre uso do corpo: releitura de um direito da personalidade. In: TEIXEIRA, Ana Carolina Brochado;

RIBEIRO, Gustavo Pereira Leita (coord.). Manual de teoria geral do direito civil. Belo Horizonte: Del Rey, 2011. p. 267-285.

STELARC. Extra era alternate anatomical architectures: a selection of projects and perfermances with prosthetics, robotics, the internet virtuality and biotechnology. [S.I.: s.n], 2019. Disponível em: http://stelarc.org/. Acesso em: 04 out. 2020.

TAYLOR, Charles. As fontes do self: a construção da identidade moderna. São Paulo: Loyola, 1997.

TEIXEIRA, Ana Carolina Brochado. Saúde, corpo e autonomia privada. Rio de Janeiro: Renovar, 2010.

TEPEDINO, Gustavo; OLIVA, Milena Donato. Fundamentos do direito civil: teoria geral do direito civil. Rio de Janeiro: Forense, 2020. v. 1.

TONG, Amber. 'Biohacker' Traywick accidentally drowned, official confirms. Endpoint News, [S.I.], 2 jul. 2019. Disponível em: https://endpts.com/biohacker-traywick-accidentally-drowned-bloomberg/. Acesso em: 13 jun. 2020.

VAIANO, Bruno. Entrevistamos os biohackers que criaram o colírio da visão noturna. Super Interessante, [S.I.], 21 dez. 2016. Disponível em: https://super.abril.com.br/blog/supernovas/entrevistamos-os-biohackers-quecriaram-o-colirio-da-visao-noturna/. Acesso em: 04 jun. 2020.

Recebido em: 06.08 .2020

Aceito em: 13.09.2021 